\title{
Congenital Bronchoesophageal Fistula in an Adult
}

\author{
Lt Col SP Rai ${ }^{*}$ Maj Gen SK Kaul, vsm ${ }^{+}$, Lt Col D Bhattacharyya\#, Lt Col I Sinha ${ }^{* *}$, Lt Col RK Choudhary ${ }^{++}$, \\ Col RK Tripathi"\#, Maj M Kashyap ${ }^{* * *}$
}

MJAFI 2005; 61 : 291-292

Key Words: Congenital; Bronchoesophageal fistula

\section{Introduction}

$\mathrm{F}_{\mathrm{b}}$ istulas between the oesophagus and the airways can be congenital or acquired. Although congenital fistula is usually identified in neonates, rarely it may not be recognized until later in life [1]. In cases of delayed recognition, there is a long history of coughing with expectoration after drinking or eating [2].They present as recurrent pneumonia, lung abscess or bronchiectesis. Barium swallow demonstrates fistula and confirms the diagnosis. Bronchoscopy and oesophagoscopy demonstrate the fistulous opening. We present a case of H-type congenital bronchoesophegeal fistula in an adult who underwent resection.

\section{Case Report}

A 41 year old lady presented with two years of cough with expectoration. Her symptoms increased after drinking or eating and at times food particles were coughed out. She gave history of recurrent chest infection, fever and streaky haemoptysis. She had right supraclavicular lymph node enlargement. Clinically and radiologically, chest was clear. Fine needle aspiration cytology of lymph node showed chronic lymphadenitis with necrosis. She was diagnosed as tubercular lymphadenitis and put on anti tubercular treatment (ATT). After eight months she developed haemoptysis and fever. Repeat chest radiograph showed lung abscess involving right lower lobe (RLL). Sputum was repeatedly negative for acid-fast bacilli. Lung abscess resolved with parenteral antibiotics. She gave history of two years ATT for pulmonary tuberculosis 20 years earlier.

The patient weighed $49 \mathrm{~kg}$, had grade I clubbing and grade I diffuse goiter. Her haemoglobin was $13.3 \mathrm{gm} \%$, ESR-28mm and Mantoux was $21 \mathrm{~mm}$. Pulmonary function test showed mild restrictive defect with FVC of 2.341 (74\% of expected normal). Fibreoptic bronchoscopy was normal. Barium swallow demonstrated H-type bronchesophageal fistula connecting lower third of oesophagus with right lower lobe (RLL) bronchi (Fig 1). Computed tomography chest with oral contrast also showed fistulous communication between oesophagus and superior and posterior segment of RLL and evidence of abscess RLL (Fig 2).

She underwent surgery through a right posterolateral thoracotomy. Fistulous track was dissected, excised and both ends were sutured. She made an uneventful recovery. Histopathology of excised fistula tract showed fibro muscular tissue. There was no evidence of malignancy or tuberculosis. Postoperative barium oesophagogram was normal.

\section{Discussion}

Bronchoesophageal and tracheoesophageal fistula are rare. They can be due to a malignant or benign process. Benign causes include trauma, inflammation or congenital. Congenital tracheoesophageal or bronchoesophageal fistula, if not associated with esophageal atresia may not appear until adult life [1]. There are scant reports of such an entity.

Gibson first reported congenital bronchoesophageal fistula in 1969 [1]. The esophagus and trachea both develop from the primitive foregut. In a 4 to 6 week old embryo, the caudal part of the foregut forms ventral diverticulum that evolves into the trachea. The longitudinal tracheoesophageal fold fuses to form a septum that divides the foregut into a ventral laryngotracheal tube and a dorsal oesophagus. The posterior deviation of the tracheoesophgeal septum causes incomplete separation of the oesophagus from the laryngotracheal tube and results in a tracheoesophageal fistula (TEF). Incomplete formation of the oesophagus is known as oesophageal atresia, which may be associated with TEFs.

Braimbridge and Keith (1966) classified congenital fistulas as Type $1(2 \%)$ : Oesophageal diverticulums with a large ostium and a fistula at its tip. Type $2(90 \%)$ : A short communication running directly from the oesophagus to the bronchus or trachea. Type $3(3 \%)$ : A

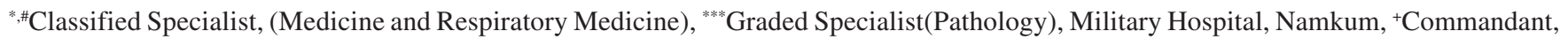
$\mathrm{CH}$ (WC), Chandimandir, ${ }^{* *}$ Classified Specialist(Radiology), Army Hospital, R\&R, Delhi Cantt., ${ }^{++}$Classified Specialist (Pathology), 155 Base Hospital, c/o 99 APO, "\#Senior Advisor (Anaesthesilogy), INHS Asvini, Mumbai.
}

Received : 16.09.2003; Accepted: 09.06.2004 


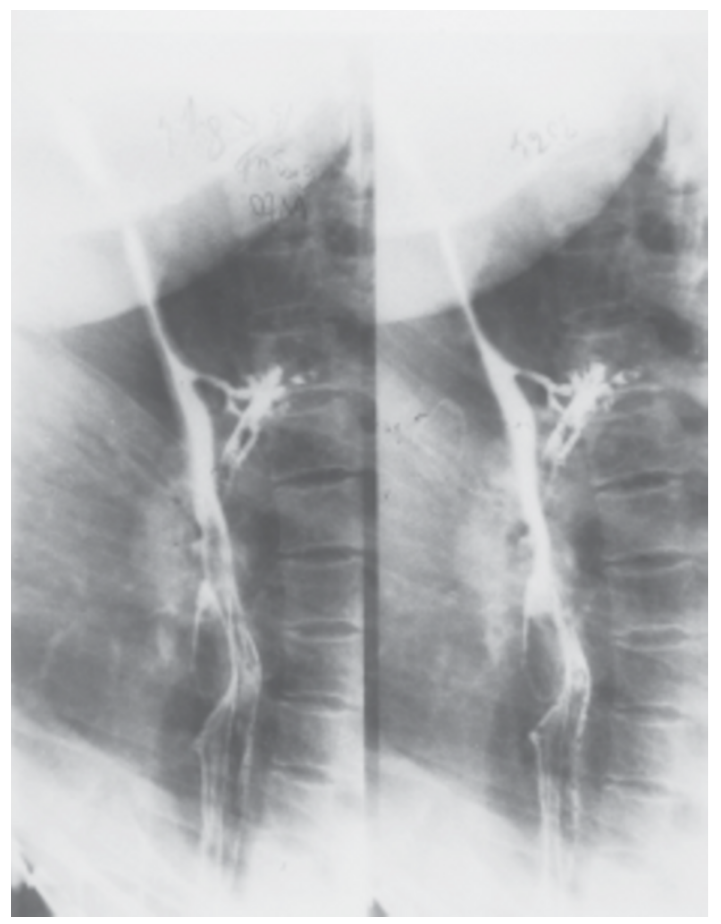

Fig. 1 : Barium swallow showing a fistulous tract connecting the oesophagus with posterior basal segment RLL

fistulous tract connecting the oesophagus to a cyst in the lobe, which in turn communicates with the bronchus. Type $4(5 \%)$ : A fistula that runs into a sequestrated segment or lobe. The H-type fistula (Type 2) in which both the trachea and oesophagus remain patent may go undetected until adult life, despite the presence of long standing recurrent symptoms [3]. The main presenting symptoms are bouts of coughing after drinking (Ohno's sign) and recurrent respiratory infection as seen in our case [2]. Other features may include haemoptysis, restrosternal pain, vague gastrointestinal symptoms and halitosis [4]. The duration of symptom can vary from six months to thirty years [5]. The long silent interval until adult-hood has been explained due to an occlusive valve like mucosal flap, a fistulous tract running upwards from the oesophagus into the bronchus that may close during swallowing, spasm of the muscular layer occluding the lumen and possibly even varying symptom tolerance.

Barium swallow is the most useful investigation and provides the diagnosis in more than $60 \%$ cases. Fistulous opening was not visualized on bronchoscopy in this patient because of involvement of segmental bronchi. Dynamic bronchoscopy with thin paediatric bronchoscope could have demonstrated the fistulous opening. Of the bronchi, the right main bronchus is commonly affected [4].

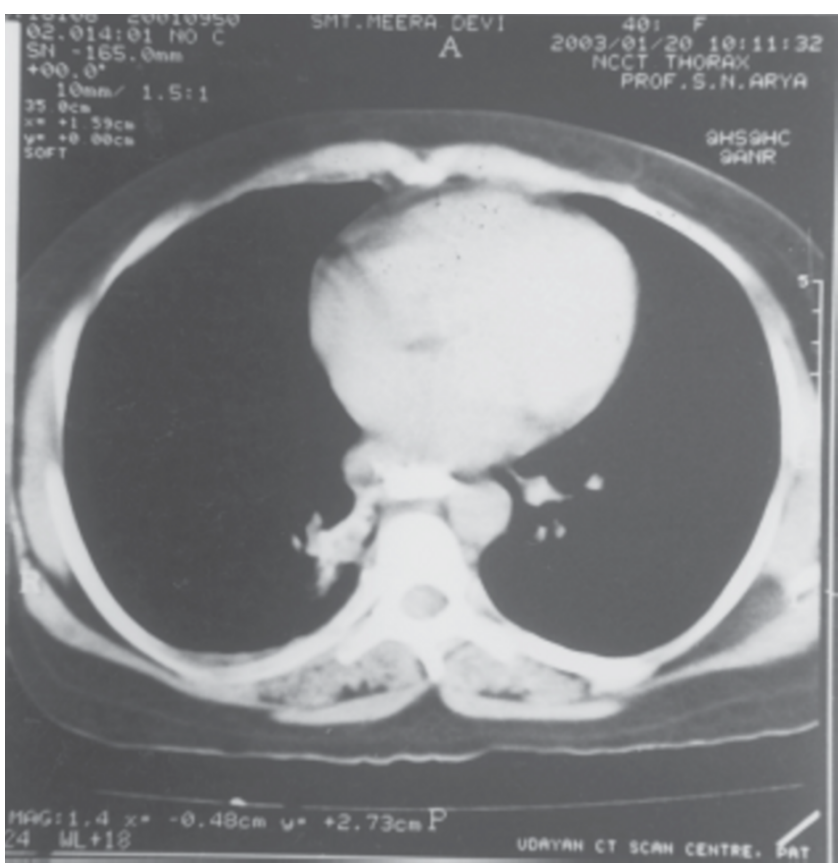

Fig. 2: CT thorax demonstrating contrast in posterior basal segmental bronchi RLL and oesophagus along with the intervening fistulous tract

Because of chronic lymphadenitis with necrosis, strongly positive mantoux and history of antitubercular treatment, we looked for tubercular etiology, but H-type obliquely oriented fistula, oesophegial end being distal to the bronchial communication, absence of inflammation and presence of intramural muscle on histopathology were suggestive of congenital bronchoesophageal fistula $[1,2]$. Prognosis is excellent in patients who undergo surgical repair [6].

\section{References}

1. Azoulay AD, Regnard JF, Maddileinat P, Diamond T. Congenital respiratory - oesophageal fistula in the adult. Report of nine case and review of literature. J Thorac Cardiovasc Surg 1992; 104: 381-4.

2. Mangi AA, Gaissert HA, Wright CD, et al. Benign bronchoesophageal fistula in the adult. Ann Thorac Surg 2000;73(3):911-5.

3. Freixinet J, Rami R, Ledo R, Corhal M, Calzadillo G, Snchez LJ. Congenital bronchoesophgeal fistula in audlts, report of three cases. Eur J Cardiothoracic Surg 1990;4: 451-3.

4. Lazopoulos G, Kotoulas C, Lioulias A. Congenital bronchoesophageal fistula in the adult. Eur J Cardiothoracic Surg 1999; 16(6): 667-9.

5. Risher WH, Arsensman RM, Octisner JL. Congenital bronchoesophageal fistula. Ann Thoracic Surg 1990; 49: 500-5.

6. Ramo OJ, Salo JA, Mattila SP. Congenital bronchoesphageal fistula in the adult. Ann Thorac Surg 1995; 59: 887-9. 